\title{
Encantando com a poesia: uma experiência criativa na Escola Daniel Batista
}

\author{
Kênia Paulino de Queiroz Souza * \\ Maria José de Pinho **
}

\begin{abstract}
Resumo
As práticas pedagógicas contemporâneas no cenário educativo com uma visão ampliada e transformadora possibilitam ressignificações em suas vivências educacionais. Com esse olhar global, o presente relato de experiências objetiva polinizar ações que caracterizem práticas pedagógicas criativas, a partir dos projetos que norteiam o funcionamento dos anos iniciais do Ensino Fundamental. Este artigo é um recorte da pesquisa de mestrado em educação 'Práticas pedagógicas criativas: uma perspectiva transdisciplinar na escola do século XXI' desenvolvida na Escola $\mathrm{Mu}$ nicipal de Tempo Integral Daniel Batista. A qual apresenta metodologicamente uma abordagem qualitativa exploratória, direcionada pelo estudo de caso. Na coleta de dados usou o questionário VADECRIE (Instrumento de valoração das práticas criativas da Rede Internacional de Escolas Criativas - RIEC) e as técnicas de entrevistas semiestruturadas, observação direta e análise de documentos (Projeto Político Pedagógico, Plano de Ação e projetos pedagógicos). De acordo com a análise parcial dos dados, a Escola Daniel Batista desenvolve uma variedade de ações diferenciadas e integradoras. A sua prática pedagógica a partir dos projetos e, principalmente, do 'projeto Declamadores de poesia' é realizada em equipe com espontaneidade, determinação, criatividade e com o reconhecimento da importância de seus objetivos educacionais estarem conectados com a vida.

Palavras-chave: criatividade, complexidade, transdisciplinaridade.
\end{abstract}

\section{Charming with poetry: a creative experience at school daniel batista}

Abstract: The contemporary pedagogical practices in the educational setting with an enlarged and transforming vision possible reinterpretation in their educational experiences. With this global view, this report aims experiences pollinate actions that characterize creative pedagogical practices from projects that guide the operation of the early years of elementary school. This article is an excerpt of the master's research in education 'creative teaching practices: a transdisciplinary perspective in the school of the XXI century' developed in Full Time School Daniel

\footnotetext{
Mestre em Educação pela Universidade Federal do Tocantins - UFT. E-mail: keniaqueiroz06@hotmail. com

** Doutora em Currículo e Educação pela PUC- SP. Professora do Mestrado em Educação e do Mestrado e Doutorado em Ensino de Língua e Literatura da Universidade Federal do Tocantins - UFT. E-mail: mjpgon@uft.edu.br
} 
Batista. Which methodologically presents an exploratory qualitative approach, directed by the case study. In the data collection used the questionnaire VADECRIE (valuation instrument of creative practices of the International Creative Schools Network - RIEC) and the techniques of semi-structured interviews, direct observation and document analysis (Political Pedagogical Project, Action Plan and educational projects). According to partial data analysis, the School Daniel Batista develop a variety of differentiated and integrative actions. The pedagogical practice from the projects, and especially the 'reciters project poetry' is held in team with spontaneity, determination, creativity and recognition of the importance of their educational goals are connected with life.

Keywords: creativity, complexity, transdisciplinarity.

Introdução

Em meio as adversidades do século XXI o repensar das ações pedagógicas no contexto educativo pode propiciar novos horizontes de superação deste cenário fragmentado e desunido que tem se apresentado na educação. Um repensar com o olhar criativo que se direciona nos caminhos da complexidade e da transdisciplinaridade.

Nessa concepção, este artigo apresenta parte dos resultados da pesquisa de mestrado em educação 'Práticas pedagógicas criativas: uma perspectiva transdisciplinar na escola do século XXI' que encontra-se em andamento com a problemática: a prática pedagógica, a partir dos projetos e ações realizados com os alunos da Escola Municipal de Tempo Integral Daniel Batista, de Palmas, apresenta indícios de criatividade?

Diante a problemática, este artigo objetiva polinizar ações que caracterizem práticas pedagógicas criativas, registradas nos projetos que norteiam o funcionamento dos anos iniciais do Ensino Fundamental. O caminho percorrido nesta pesquisa com abordagem qualitativa exploratória, é pelo o estudo de caso por ser um caso único a ser investigado e por este caminho propiciar um estudo minucioso (ANDRÉ, 2013). Para levantamento dos dados foi utilizado como instrumento o questionário VADECRIE (Instrumento de valoração das práticas criativas da Rede Internacional de Escolas Criativas-RIEC) e as técnicas: observação direta, análise de documentos e entrevistas semiestruturadas. Neste trabalho não serão apresentados os dados do VADECRIE que ainda, encontra-se em análise, das entrevistas realizadas com gestores, professores, alunos e pais, foram analisadas neste artigo de: uma coordenadora, uma professora e um aluno. Os quais serão identificados pela letra inicial que cada um representa na Unidade de Ensino: coordenadora (C), professora (P) e aluno (A), buscando preservar a identidade dos sujeitos.

Para complementar o estudo, analisou-se os documentos: Projeto Político 
Pedagógico (PPP), Plano de Ação e os projetos pedagógicos desenvolvidos com os alunos da instituição. A fundamentação bibliográfica, pautou-se nos principais aportes teóricos: Nicolescu (1999), Morin (2000; 2007), Torre (2005; 2009), Moraes (2008), Zwierewicz (2012; 2013), Suanno (2013), dentre outros. Estas obras trazem a compreensão de que há seres humanos e instituições que vivem em constante mudanças em busca de novos saberes que agregam sentidos à vida numa dimensão criativa.

Para Torre (2009) a criatividade vai além da exclusividade referente ao novo e original, está no olhar diferenciado para o contexto educativo, uma visão ampliada e integradora que busca as superações de situações conflitos, as transformações e a geração de ações coletivas, humanas e criativas, aproveitando as oportunidades das provocações que o ambiente produz.

\title{
Criatividade: uma visão complexa e transdisciplinar na educação
}

Os caminhos de criatividade estão presentes em diferentes contextos da sociedade, mas quando traz a atenção para o campo da educação e especificamente à escola, percebe-se que um desafio é enfrentado na acepção de reconhecer práticas pedagógicas com indícios de criatividade. Para Torre (2008), no cenário educativo

\begin{abstract}
a criatividade começa a ser entendida como uma qualidade não exclusiva dos indivíduos, mas também das organizações, comunidades, povos e culturas. A criatividade a partir de um paradigma da complexidade e da interação sociocultural é um potencial que aflora ali onde se dão as condições e climas apropriados para que aflorem ideias novas, sem temor de serem rejeitadas. Valorizadas como gérmen de mudanças, deixam cada vez mais evidente que a pessoa e o ambiente ou o contexto organizativo não são realidades independentes e sim complementares (TORRE, 2009, p. 57).
\end{abstract}

Esta concepção de criatividade explicitada por Torre (2009) apresenta uma interligação com a perspectiva complexa e transdisciplinar que envolve o cenário educativo ao planetário. Complexa ao perceber a importância do olhar global onde a vida está conectada com o outro, com o ambiente, apesentando-se em múltiplas referências e várias dimensões. E transdisciplinar por valorizar a integração de ambiente e pessoas, além de culturas e contextos diversos. Em contrapartida, Morin (2000) afirma que um dos principais problemas na educação é a 
[...] inadequação cada vez mais ampla, profunda e grave entre, de um lado, os saberes desunidos, divididos, compartimentados e, de outro, as realidades ou problemas cada vez mais multidisciplinares, transversais, multidimensionais, transnacionais, globais e planetários (MORIN, 2000, p. 36).

A interligação entre a escola e a vida externa ao espaço educativo potencializa os estudos e propicia novos sentidos ao ensino e aprendizagem. Esta conexão é a valorização do todo, uma perspectiva complexa no desenvolvimento de ações pedagógicas no cenário educacional. Para Morin (2000),

Complexus significa o que foi tecido junto; de fato, há complexidade quando elementos diferentes são inseparáveis constitutivos do todo (como o econômico, o político, o sociológico, o psicológico, o afetivo, o mitológico), e há um tecido interdependente, interativo e inter-retroativo entre o objeto de conhecimento e seu contexto, as partes e o todo, o todo e as partes, as partes entre si (Morin, 2000, p. 38, grifos do autor).

O autor fala da união entre a complexidade e a simplicidade, todo e partes embrenhados em um contexto que envolve distintas dimensões da vida. Morin (2000, p. 38) afirma ainda, que o ser humano "[...] é ao mesmo tempo biológico, psíquico, social, afetivo e racional. A sociedade comporta as dimensões histórica, econômica, sociológica, religiosa... O conhecimento pertinente deve reconhecer esse caráter multidimensional e nele inserir estes dados [...]". A educação precisa estar ligada à vivencia planetária englobando o todo da vida humana, social e ambiental.

Com esse olhar integrador Morin (2007, p. 22), explicita que "a complexidade e a transdisciplinaridade são dois termos inseparáveis que remetem um ao outro. [...] a complexidade exige a transdisciplinaridade". Essa conexão ocorre pela perspectiva transdisciplinar de religar diversos saberes transitando e conectando contextos distintos que propiciam novos sentidos, pois, "a transdisciplinaridade não é um mero movimento epistemológico, disciplinar ou cultural; é antes de tudo, um novo olhar que tem sua projeção na vida e no âmbito social" (TORRE; et al., 2008, p. 31).

Segundo Nicolescu, "o advento de uma cultura transdisciplinar, que poderá contribuir para a eliminação das tensões que ameaçam a vida em nosso planeta, é impossível sem um novo tipo de educação, que leve em conta todas as dimensões do ser humano" (1999, p. 141, grifos do autor). O cenário escolar aberto às mudanças tanto interior quanto exterior no desenvolvimento de práticas pedagógicas que integram-se vidas e saberes podem propiciar transformações para o presente e futuro século. 
Moraes (2008, p. 101) afirma que, "a complexidade da realidade, exige também outras formas de explicação ou de interpretação da realidade e incentiva a criatividade, bem como a combinação de determinados tipos de estratégias, epistemológica e metodologicamente compatíveis [...]". Essa criatividade está relacionada com uma responsabilidade social, em contribuir com mudanças no ambiente educativo.

$\mathrm{Na}$ ótica transdisciplinar, o "[...] aprender a fazer é um aprendizado da criatividade. Fazer também significa fazer o novo, criar, trazer suas potencialidades criativas à luz" (NICOLESCU, 1999, p. 144, grifos do autor). Nesse sentido, a criatividade percebida

Essa concepção de criatividade quando percebida por meio de "[...] uma visão complexa pressupõe e exige um olhar transdisciplinar que compreende que, para se caminhar em linha com essa perspectiva da ciência, nenhuma etapa deve ocorrer apenas em âmbito individual, tampouco em contextos isolados entre si” (RIBEIRO; MORAES, 2014, p. 94). Também, compreende-se que:

[...] criatividade é o resultado da interação de um sistema composto por três elementos: uma cultura que contém regras simbólicas, uma pessoa que acrescente algo novo a uma situação existente e um conjunto de especialistas que reconhecem e validam a inovação.

[...] Posto que a criatividade está constituída conjuntamente pela interação entre situação, âmbito e pessoa, um rasgo de criatividade pessoal pode ajudar a gerar a novidade que modifica a dita situação, mas não é uma condição suficiente nem necessária para isso (CSIKSZENTMIHALYI, 1998, apud, PRAUN; GONÇALVES, 2009, p. 141).

Nesse sentido, a criatividade não resulta apenas no caracterizado como novidade, uma vez que o ato de expressar livremente gera ações que podem modificar uma determinada situação e trazer visões diferenciadas que contribuem com o outro, com a sociedade e até mesmo com o ambiente ao seu entorno. Essa acepção de criatividade na instituição educativa, se materializa em atitudes e ações que vão além do esperado fazendo bem a si e ao outro ao mesmo tempo, que visa superar os desafios trabalhando coletivamente e se transformando em um bem social (TORRE, 2009).

Com esse olhar, Torre (2005) afirma que as atividades criativas no âmbito escolar buscam transformar uma dada circunstância indesejável em situações que vão além de simples resoluções, são ações que transformam em um bem coletivo e despertam o ser criativo. Torre (2008), explicita ainda, que este ser, é aquele que consegue ver 
mais que suas próprias necessidades ao deixar florescer em seu interior o desejo de superar os infortúnios da vida e ir em busca de um bem - estar para si e ao seu entorno.

\section{Cenário pedagógico da Escola Daniel Batista}

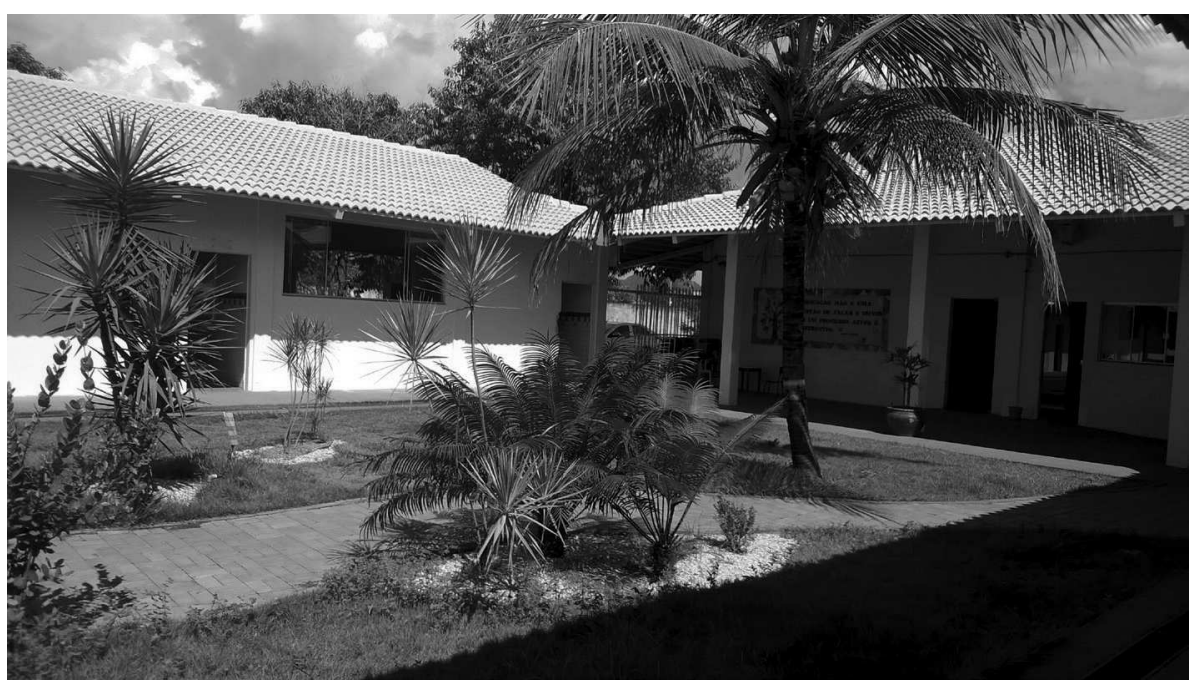

Fig. 1- Escola Municipal de Tempo Integral Daniel Batista.

Fonte: Arquivo da pesquisa 'Práticas pedagógicas criativas: uma perspectiva transdisciplinar na escola do século XXI

Conhecer o contexto histórico de uma instituição de ensino possibilita a melhor compreensão de seu cenário contemporâneo. Conhecimento este que impulsiona a ressignificação de diversas ações diferenciadas e integradoras com novos olhares. A criatividade é um fenômeno que faz-se presente não apenas a partir do potencial humano em querer superar os seus desafios, mas também são ações que levam em consideração elementos culturais e um ambiente que propicia um bem social (TORRE, 2005).

A Unidade de Ensino investigada, Escola Municipal de Tempo Integral Daniel Batista emergiu de um passado de ações diferenciadas que ainda hoje estão guardadas na memória de sua equipe educativa. Essa escola está situada na cidade de Palmas, Tocantins. Entretanto a sua origem foi na extinta comunidade Canela, povoado próximo a cidade de Palmas, em 1981 (ESCOLA MUNICIPAL DE TEMPO INTEGRAL 
DANIEL BATISTA, 2014a). No ano de 2000, com a construção da Usina Hidrelétrica Luiz Eduardo Magalhães, essa comunidade remanejou-se ao território urbano onde encontra-se até hoje. Momentos difíceis para aquela população, pois viram naquele momento, suas casas e histórias sendo inundadas pelo Rio Tocantins, ficando apenas em suas memórias e em alguns arquivos todo um passado cheio de emoções.

Após alguns desencontros em relação ao local específico para atender educacionalmente as crianças e os adolescentes daquela comunidade, só em 2002 foi inaugurado um novo prédio para a Escola Daniel Batista. Nome este em homenagem ao senhor que iniciou o trabalho educativo juntamente com a senhora Maria de Lourdes Abreu Lima, que voluntariamente cedeu sua própria casa, para iniciar as primeiras aulas no povoado Canela, em 1981 (ESCOLA MUNICIPAL DE TEMPO INTEGRAL DANIEL BATISTA, 2014a).

Em situações desafiadoras como esta, Torre (2012, p. 23) afirma que "a chave não está nos acontecimentos, mas sim no que fazemos com eles, na atitude que temos para enfrenta-los". Assim foram as atitudes destes dois senhores, diante da necessidade de uma educação formal naquela comunidade, pois a falta de recursos não os intimidaram, ao contrário, se doaram àquelas crianças, contribuindo com a fundação da Unidade de Ensino, que hoje tornou-se bem reconhecida no município de Palmas pelo seu trabalho prestado à comunidade e por sua diversidade de projetos e ações voltadas aos alunos. Segundo Suanno (2013, p. 38), esse pensamento direcionado ao planejamento no contexto escolar é considerado como "[...] uma grandiosa ferramenta para propiciar [...]" mudanças. Essa diversidade de atividades é explicitada no quadro 1:

Quadro 1 - Ações e projetos da Escola Municipal de Tempo Integral Daniel Batista

\begin{tabular}{|c|c|c|c|}
\hline Ação/ou projeto & Objetivo & $\begin{array}{c}\text { Público } \\
\text { envolvido }\end{array}$ & Período \\
\hline $\begin{array}{l}\text { 1. Momento } \\
\text { cívico }\end{array}$ & $\begin{array}{l}\text { Integrar os alunos e resgatar os valores cívicos } \\
\text { com envolvimento nas ações culturais. }\end{array}$ & $1^{\circ}$ ao $9^{\circ}$ ano & Quinzenal \\
\hline $\begin{array}{l}\text { 2. Jogos } \\
\text { interclasses }\end{array}$ & $\begin{array}{l}\text { Integrar os alunos através da prática desportiva, } \\
\text { de forma lúdica e cooperativa. }\end{array}$ & $1^{\mathrm{a}}$ e $2^{\mathrm{a}}$ fase & $\begin{array}{l}\text { Anual } \\
\text { (1semana) }\end{array}$ \\
\hline $\begin{array}{l}\text { 3. Alunos } \\
\text { destaques e } \\
\text { revelação }\end{array}$ & Homenagear os alunos destaques e revelação. & $1^{\mathrm{a}}$ e $2^{\mathrm{a}}$ fase & Bimestral \\
\hline 4. Dia das mães & $\begin{array}{l}\text { Homenagear as mães e integrar a família e a } \\
\text { escola. }\end{array}$ & $1^{\mathrm{a}}$ e $2^{\mathrm{a}}$ fase. & Anual \\
\hline $\begin{array}{l}\text { 5. Aniversário da } \\
\text { escola }\end{array}$ & $\begin{array}{l}\text { Comemorar o aniversário da escola resgatando } \\
\text { a sua história. }\end{array}$ & $1^{\mathrm{a}}$ e $2^{\mathrm{a}}$ fase & Anual \\
\hline
\end{tabular}




\begin{tabular}{|c|c|c|c|}
\hline 6. Festa Junina & $\begin{array}{l}\text { Integrar a comunidade escolar com a } \\
\text { manifestação cultural de caráter popular, com } \\
\text { danças, brincadeiras e comidas típicas. }\end{array}$ & $1^{\text {a }}$ e $2^{\text {a }}$ fase & Anual \\
\hline $\begin{array}{l}\text { 7. Mostra } \\
\text { cultural; }\end{array}$ & $\begin{array}{l}\text { Incentivar a participação dos alunos nas } \\
\text { atividades culturais, esportivas e artísticas com } \\
\text { gincanas do conhecimento, danças e músicas. }\end{array}$ & $2^{\text {a }}$ fase & Trimestral \\
\hline $\begin{array}{l}\text { 8. Projeto } \\
\text { Estudar é o meu } \\
\text { maior tesouro }\end{array}$ & $\begin{array}{l}\text { Proporcionar aos alunos da escola [...] incentivo } \\
\text { para melhorar o processo ensino e aprendizagem } \\
\text { e conscientização de ser papel social na escola. }\end{array}$ & $1^{\text {a fase }}$ & Mensal \\
\hline $\begin{array}{l}\text { 9. Campeonato } \\
\text { de futsal }\end{array}$ & Integrar os alunos por meio do esporte. & $2^{\mathrm{a}}$ fase & $\begin{array}{l}\text { Anual } \\
\text { (1semana) }\end{array}$ \\
\hline $\begin{array}{l}\text { 10. Dia dos } \\
\text { pais/ Dia 'D' da } \\
\text { família }\end{array}$ & $\begin{array}{l}\text { Integrar escolar-família e abordar o tema, } \\
\text { Importância da Família durante o período das } \\
\text { aulas da base comum. }\end{array}$ & $\begin{array}{l}1^{\mathrm{a}} \text { e } 2^{\mathrm{a}} \text { fase } \\
\text { e família. }\end{array}$ & Anual \\
\hline $\begin{array}{l}\text { 11. Projeto } \\
\text { Diversidade e } \\
\text { inclusão }\end{array}$ & $\begin{array}{l}\text { Oportunizar aos alunos da escola a participação } \\
\text { em eventos culturais e educativos, garantindo } \\
\text { assim igualdade de direito a todos; favorecer a } \\
\text { inclusão social e valorizar potenciais [...]. }\end{array}$ & $1^{\text {a }}$ e $2^{\text {a }}$ fase & $\begin{array}{l}\text { Anual } \\
\text { (1semana) }\end{array}$ \\
\hline $\begin{array}{l}\text { 12. Festival da } \\
\text { criança }\end{array}$ & $\begin{array}{l}\text { Comemorar com brincadeiras e gincanas o dia } \\
\text { da criança. }\end{array}$ & $1^{\mathrm{a}}$ e $2^{\mathrm{a}}$ fase & Anual \\
\hline $\begin{array}{l}\text { 13. Basquete de } \\
\text { rua }\end{array}$ & $\begin{array}{l}\text { Integrar os alunos através da prática desportiva, } \\
\text { de forma lúdica e cooperativa. }\end{array}$ & $2^{\mathrm{a}}$ fase & Anual \\
\hline $\begin{array}{l}\text { 14. Projeto } \\
\text { Declamadores } \\
\text { de poesia }\end{array}$ & $\begin{array}{l}\text { Desenvolver a leitura e oralidade e proporcionar } \\
\text { aos alunos o contato com autores regionais. }\end{array}$ & $1^{\mathrm{a}}$ e $2^{\mathrm{a}}$ fase & $\begin{array}{l}\text { Anual } \\
(1 \text { mês })\end{array}$ \\
\hline 15. Maratoninha & $\begin{array}{l}\text { Estimular os alunos a participar de exercícios } \\
\text { físicos, tendo a corrida como principal } \\
\text { modalidade, visando a qualidade de vida. }\end{array}$ & $1^{\mathrm{a}}$ e $2^{\mathrm{a}}$ fase & $\begin{array}{l}\text { Anual } \\
\text { (1semana) }\end{array}$ \\
\hline $\begin{array}{l}\text { 16. Feira de } \\
\text { ciências }\end{array}$ & $\begin{array}{l}\text { Estimular os alunos a realizar experiências que } \\
\text { envolve a tecnologia, o ambiente e a vida. }\end{array}$ & $1^{\mathrm{a}}$ e $2^{\mathrm{a}}$ fase & $\begin{array}{l}\text { Anual } \\
(1 \text { mês })\end{array}$ \\
\hline $\begin{array}{l}\text { 17. Dia } \\
\text { pedagógico }\end{array}$ & \begin{tabular}{|l|} 
Discutir sobre os assuntos pertinentes ao \\
Pedagógico com palestras e oficinas.
\end{tabular} & $\begin{array}{l}\text { E q u i p e } \\
\text { pedagógica }\end{array}$ & Bimestral \\
\hline $\begin{array}{l}\text { 18. Projeto } \\
\text { Halloween }\end{array}$ & Propiciar vivências com culturas diversas. & $1^{\mathrm{a}}$ e $2^{\mathrm{a}}$ fase & $\begin{array}{l}\text { Anual } \\
\text { (1semana) }\end{array}$ \\
\hline $\begin{array}{l}\text { 19. Dia Nacional } \\
\text { da Consciência } \\
\text { Negra }\end{array}$ & $\begin{array}{l}\text { Refletir sobre a cultura afro brasileira e realizar } \\
\text { apresentações culturais e artísticas. }\end{array}$ & $1^{\mathrm{a}}$ e $2^{\mathrm{a}}$ fase & $\begin{array}{l}\text { Anual } \\
(1 \mathrm{mês})\end{array}$ \\
\hline $\begin{array}{l}\text { 20. Projeto } \\
\text { Lendo na escola }\end{array}$ & $\begin{array}{l}\text { Apoiar a comunidade escolar na realização } \\
\text { de ações e projetos de incentivo à leitura [...]; } \\
\text { desenvolver a criatividade e a imaginação; }[\ldots] .\end{array}$ & $1^{\mathrm{a}}$ e $2^{\mathrm{a}}$ fase & Quinzenal \\
\hline
\end{tabular}




\begin{tabular}{|l|l|l|l|}
\hline $\begin{array}{l}\text { 21. Projeto } \\
\text { Escola legal é } \\
\text { escola limpa }\end{array}$ & $\begin{array}{l}\text { Promover ações que levem à reflexão dos alunos e } \\
\text { professores sobre a importância de um ambiente } \\
\text { limpo e organizado. }\end{array}$ & $1^{\text {a }}$ e 2 $2^{\text {a }}$ fase & $\begin{array}{l}\text { Anual } \\
\text { (1semestre) }\end{array}$ \\
\hline
\end{tabular}

Fonte: Quadro elaborado com base no PPP da Escola Municipal de Tempo Integral Daniel Batista (2014a; 2014b; 2015). Arquivo da pesquisa 'Práticas pedagógicas criativas: uma perspectiva transdisciplinar na escola do século XXI

A partir dessa variedade de atividades pedagógicas e da observação de suas realizações no centro educativo, percebe-se que a equipe prima por um trabalho diferenciado para desenvolverem a educação integral, entretanto integral não no sentido de espaço de tempo ampliado, mas sim que atenda o discente como um todo, preparando-o para a vida de forma prazerosa. Segundo Nascimento (2013, p. 93) "o gosto pela aprendizagem é desenvolvido quando o aluno sente-se construtor de seu próprio saber."

Dentre as ações (quadro 1), ressalta-se a 'Maratoninha', uma das atividades desenvolvidas pela escola, pois, "[...] é um projeto voltado para estimular os alunos a praticar exercícios físicos, tendo a corrida como principal modalidade, visando à qualidade de vida" (ESCOLA MUNICIPAL DE TEMPO INTEGRAL DANIEL BATISTA, 2014a). Esta atividade conta com a participação dos pais e voluntários, além de toda a comunidade educativa; trabalhando tanto a importância da atividade física quanto a reeducação alimentar para a saúde dos alunos e sua família. Esta ação desenvolvida pela equipe pedagógica, desperta “[...] a busca permanente de um ensinar, um aprender e um viver saudável [...]" (DITTRICH, ESPINDOLA, KOEFENDER, 2013, p. 172).

Esta busca continua com a realização de outras atividades, uma vez que, o 'Momento cívico' é uma ação quinzenal desenvolvida de forma integrada com o 'Projeto Lendo na escola'. Estas atividades contam com a participação de todos da Escola, tanto em sala de aula quanto em apresentações culturais com a finalidade de trabalhar a cidadania, a cultura, os valores sociais e ambientais, a leitura, a escrita e a arte; bem como em "desenvolver a criatividade e a imaginação" (ESCOLA MUNICIPAL DE TEMPO INTEGRAL DANIEL BATISTA, 2015, p.3). Porquanto, eles motivam a participação do educando como protagonista de seu próprio conhecimento de forma prazerosa (NASCIMENTO, 2013).

Outro projeto que compõe o processo de ensino e aprendizagem na escola é o 'Estudar é o meu maior tesouro', realizado com os alunos dos anos iniciais do Ensino Fundamental cotidianamente, em conjunto com a equipe gestora, professores e pais. Esta ação, objetiva "contribuir para o desenvolvimento da responsabilidade e organi- 
zação do estudante, observando as dificuldades que cada um tem para aprender [...]" (ESCOLA MUNICIPAL DE TEMPO INTEGRAL DANIEL BATISTA, 2014a, p.3); para tanto, esta atividade tem "[...] por finalidade a integração e socialização dos educandos de forma inovadora e divertida" (NASCIMENTO, 2013, p. 93).

Nesse sentido, os objetivos (quadro 1) da prática pedagógica da Escola Daniel Batista buscam a integração e o desenvolvimento de projetos e ações que valorizam uma realização coletiva, livre, criativa e espontânea incentivando a participação ativa do aluno como protagonista de sua aprendizagem, e ainda, que este seja preparado à vida presente e futura nas dimensões humana, social e planetária.

\section{Experiência criativa no mundo da poesia}

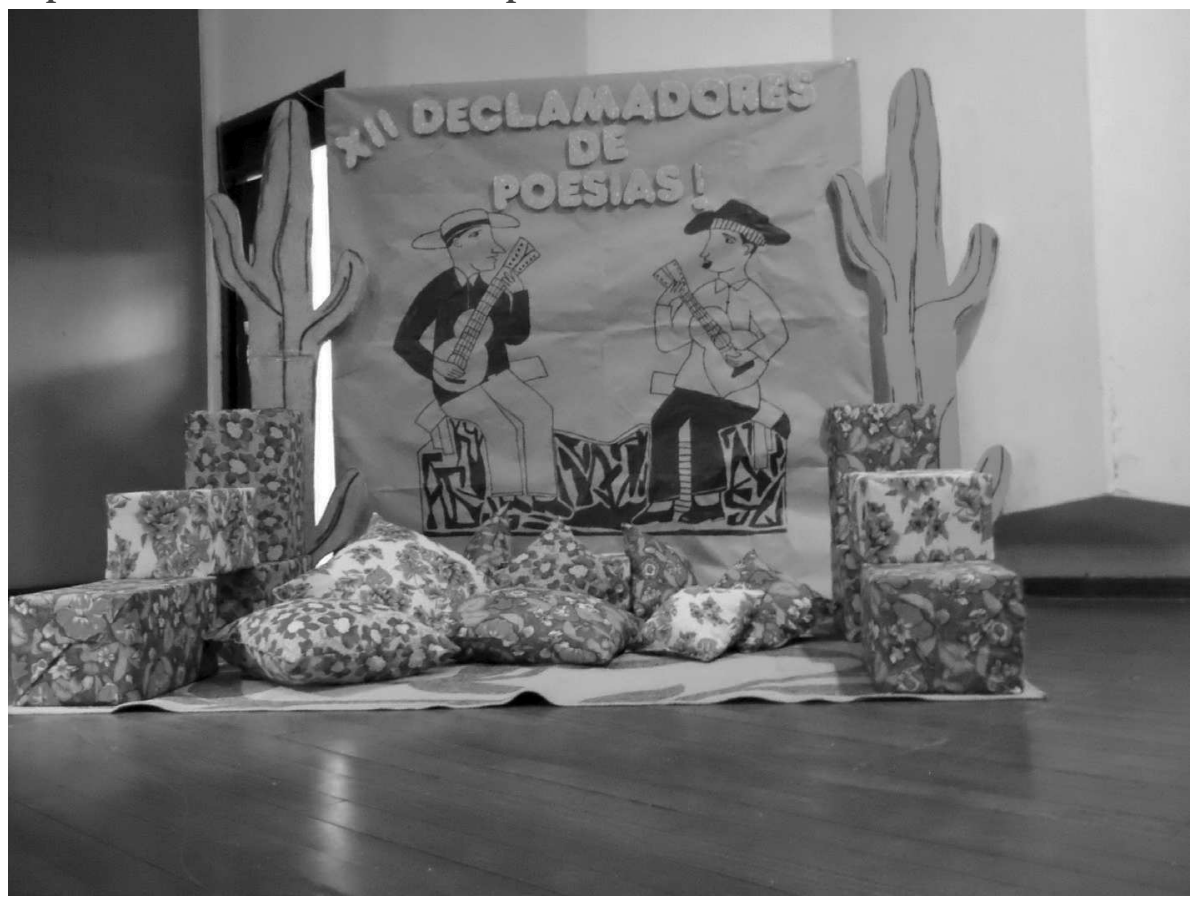

Fig. 2- Parte do cenário do XII Declamadores de poesia.

Fonte: Arquivo da Escola Daniel Batista

O projeto 'Declamadores de Poesia' é reconhecido pela comunidade palmense como uma das ações exitosas que a Escola Daniel Batista desenvolve. Essa ação vem sendo realizada desde o ano de 2002, o qual surgiu com o objetivo de 
superar os desafios referente a leitura e a escrita, em um momento que sinalizava a necessidade de atitudes que possibilitassem mudanças (ESCOLA MUNICIPAL DE TEMPO INTEGRAL DANIEL BATISTA, 2014b). Nesse sentido, a valorização do contexto histórico da escola foi percebida como oportunidade de propiciar avanços com novos passos e ressignificar o próprio fazer pedagógico (RAJADELL, 2012).

As experiências vivenciadas pela escola desde a comunidade Canela, tem contribuído para o incentivo de transformações nas práticas pedagógicas que objetivam agregar novos conhecimentos e superar os seus desafios educativos.

Nessa acepção, em busca de mudanças, a coordenadora (C), relata como surgiu as primeiras sementinhas do projeto 'Declamadores de poesia':

Em 2002 tinha a nossa secretária [...]. E eu na biblioteca. [...] tínhamos muitos alunos da zona rural que não sabiam ler e [...] não tinha nenhum incentivo, [...] era aqueles alunos que... era só cachaça, alunos que eu comecei trabalhar teatro, [...] a mudança deles veio a partir do teatro e da poesia. Você sentava com eles para conversar, menino de dezoito anos, eles nunca sentaram numa mesa com o pai para conversar, para almoçar, não existia isso. E a gente foi fazendo essa transformação, eu e a secretária. (C).

As duas educadoras perceberam a importância de se unirem para realizarem uma ação interventiva a partir da leitura, uma vez que naquela época os alunos estavam com dificuldades na leitura e escrita, e ainda com distorção de idade e série. As duas iniciaram um trabalho diferenciado com o intuito de ver seus educandos participativos, assim como desenvolvendo as habilidades propostas para cada ano/série e acreditando que aquela situação poderia ser revertida em outro cenário. Para Torre e Zwierewicz, "[...] a verdadeira fonte da aprendizagem está na vida. E é a vida que deveria ser o ponto de partida para construir o currículo e o ponto de chegada que se define em suas diferentes manifestações profissionais e sociais" (2012, p. 11, grifos dos autores).

Com a arte e o prazer que a poesia propicia, o projeto 'Declamadores de poesia' é organizado e planejado anualmente a partir desse pensamento integrador. Com o olhar ampliado inicia-se com uma reunião envolvendo toda equipe educativa para decidir a temática. Os alunos (de toda a escola) são convidados a declamarem e a realizarem apresentações culturais no 'Concurso de poesias' (uma das ações do projeto), conforme explicita a figura 3: 


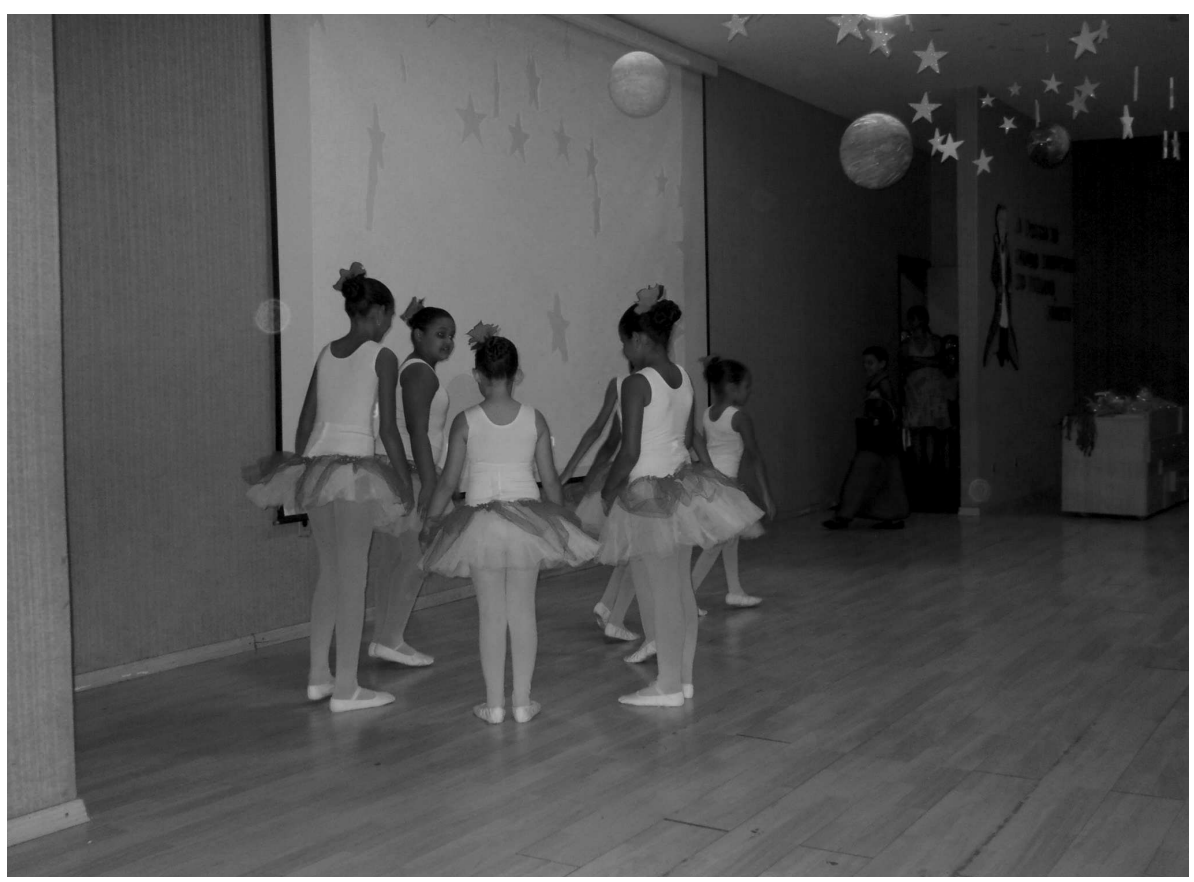

Fig. 3 - Apresentação cultural no 'Concurso de poesia'.

Fonte: Arquivo da Escola Daniel Batista

Todo um trabalho de preparação, diálogo e envolvimento com o mundo da poesia antecede esse 'Concurso', pois buscam maior contato com leituras, pesquisas, produções textuais, teatro, música, arte e encontros com escritores tocantinenses (ESCOLA MUNICIPAL DE TEMPO INTEGRAL DANIEL BATISTA, 2014b).

Esta realização tem propiciado a descoberta de vários potenciais, alunos que não demonstravam condições de declamar ou se apresentar em público revelaram-se em grandes talentos. $\mathrm{O}$ aluno (A), descreve a sua experiência com o projeto:

[...] a gente entra em outro mundo. Assim... nós vamos declamar. Só de ter a coragem de ir lá, o resultado é muito bom.

[...] eu sou muito tímido. Sou tímido pra tudo. A maioria são. [...] eu aprendi a interagir com o público. E tirar a timidez.

[...] tinha outras pessoas já experientes a muito tempo (participando do Concurso). Eu não tinha esperança de ganhar. Porque era minha primeira vez. 
[...] na minha primeira vez que participei, [...] fui vestido de palhaço que era minha poesia 'Dia de Palhaço', [...] eu não tinha nenhuma experiência e [...] marcou muito porque ganhei em segundo lugar.

Eu nem imaginava, porque foi muita alegria, chamou o terceiro lugar e o segundo, pensei que não tinha mais chances [...]. E quando chamou meu nome... fiquei muito feliz.

[...] no sexto ano [...] incentivei meu colega, porque ele era mais tímido do que eu, e ele teve coragem de ir.

[...] O projeto pra mim, é cultura, incentivo à leitura, e também uma superação.

[...] a escola é muito boa, ajuda [...] ter um futuro melhor, e ser alguém na vida. (A).

Nesse sentido, a professora entrevistada (P), afirma que: "o Declamadores ajuda bastante na oralidade, a desinibir a criança, [...] desenvolver mais a leitura, [...]” (P). Segundo a sua concepção de criatividade na realização dos projetos, a docente destacou que "[...] no Declamador, é aonde você percebe mais na questão do dia da culminância [Concurso de poesia], [...] tem sempre [...] alguma inovação nas apresentações [...]" (P).

Estes relatos demonstram o quanto a equipe educativa se esforça para que haja mudanças em seu cenário de aprendizagem. Diante disso, Torre (2012, p. 47) fala: "Cultive sua força de vontade, sua constância em projetos iniciados, fixando-se em pequenos desafios ou exigências". De acordo com o autor e os relatos dos entrevistados, observa-se que os educandos têm cultivado seus potenciais, assim como os educadores tem buscado atingir as metas propostas para o ensino e aprendizagem.

Quanto às metas do 'projeto Declamadores de poesia', desde 2002, tem passado por diversas reestruturações, sendo reavaliado anualmente, contudo, vem sendo preservada desde o início, a pretensão de estimular os alunos a desenvolverem uma leitura prazerosa. Percebe-se que em 2014, o objetivo geral foi: "viver a leitura poética de uma forma plena e prazerosa por meio da declamação" (ESCOLA MUNICIPAL DE TEMPO INTEGRAL DANIEL BATISTA, 2014b, p.03). E específicos:

Enriquecer a bagagem cultural dos participantes; Despertar o gosto pela leitura de obras de referências e locais; Incentivar que os alunos criem seus próprios poemas; Entender que textos poéticos devem ser lidos com entonação certa; Compreender a melhor forma de se portar num palco e falar em público; Despertar o gosto pelo declamar poesias (ESCOLA MUNICIPAL DE TEMPO INTEGRAL DANIEL BATISTA, 2014b, p. 03-04). 
Diante os objetivos, compreende-se que o projeto busca trabalhar vários eixos de diversas disciplinas, bem como transcendê-las preparando o educando para a vida a partir do incentivo à expressão, liberdade, o compartilhar ideias, criar livremente segundo o seu potencial, favorecendo a si mesmo, a sua volta e o seu meio com um olhar ampliado, do todo à vida planetária (MORIN, 2001).

Essa perspectiva educacional é imprescindível na contemporaneidade, segundo Zwierewicz (2012, p. 53) "[...] a capacidade criativa tornou-se uma premissa da sobrevivência planetária, especialmente, quando a potencialidade [...] transformam situações adversas em oportunidades para o bem - estar individual, social e ambiental [...]". Com esse olhar, percebe-se que o referido projeto apresenta indícios de criatividade, uma vez que o mesmo vai além de um objetivo meramente cognitivo, busca a integração de diversas áreas do conhecimento e em diferentes contextos inter-relacionam entre si (NICOLESCU, 1999).

Para Torre e Zwierewicz (2009),

[...] um bom projeto já é por si criativo se respeita a iniciativa dos discentes, se promove a criatividade e a busca de alternativas, se fomenta o diálogo, a atitude de busca colaborativa, a capacidade expressiva em suas diversas manifestações.

Todo projeto que se orienta para o desenvolvimento pessoal e, portanto, promove a responsabilidade, a autonomia, o sentido crítico, a capacidade de tomar decisões, a busca de soluções para os problemas, está favorecendo a criatividade (p. 155).

Nessa concepção o 'projeto Declamadores de poesia' tem se apresentado. Para a coordenadora (C): “[...] a maior gratificação é quando vê aquelas crianças brilhar. [...] Quando falo do Declamador, dos meninos, eu seguro para não chorar [...]” (C). Esse relato demonstra que a educadora desenvolve o trabalho visando o crescimento do aluno mais que de qualquer outro integrante da equipe, embora seja possível perceber que todos crescem nesta ação pedagógica; pois “[...] a própria equipe se transformou em um entorno polinizador, cujo pólen segue voando pelos ares e se aconchegando em terras sedentas por sementes que ao germinar, movem a realidade, trazendo para ela novas esperanças e realizações sustentáveis" (ZWIEREWICZ, 2013, p.174). Nessa perspectiva, a Escola Daniel Batista tem buscado desenvolver um trabalho coletivo e integrado à sua realidade contemporânea. 


\section{Considerações finais}

O desenvolvimento das práticas pedagógicas a partir dos projetos e ações na Escola Daniel Batista, até o presente momento, têm apresentado indícios de criatividade pautados nos valores humanos, sociais e ambientais, segundo as concepções dos autores estudados e a prévia análise parcial dos resultados desta pesquisa. Observa-se, que a equipe da instituição, prioriza um olhar mais humano e global para o desenvolvimento de suas atividades e procura ir além do previamente estabelecido em suas diretrizes.

Dentre a diversidade de ações da escola, percebe-se que o 'projeto Declamadores de poesia' apresenta indícios de criatividade por ter sido desenvolvido com o intuito de propiciar aos educandos, condições de espontaneamente se expressarem com liberdade, integrando diversas áreas do conhecimento, bem como valores, atitudes e diferentes ideias; além de sua autonomia em decidirem o quê e como se apresentar, pensando em um bem para si e para todos a sua volta.

Nesse sentido, a pesquisa instiga novas curiosidades, por exemplo: como o 'Projeto Declamadores de poesia' poderia ir além? Poderia talvez agregar em seu desenvolvimento, ações que interligam os valores ambientais ao mundo da poesia? Questionamentos estes que partem da compreensão de que o olhar complexo amplia as perspectivas de desenvolvimento das práticas pedagógicas sinalizando a importância de ações educativas serem pensadas e repensadas com a integração dos valores ambientais, além dos individuais e sociais. São integrações imprescindíveis ao desenvolvimento da vida planetária, a qual complementa a realização de uma ação educativa exitosa.

Nessa perspectiva, Torre (2012), afirma que a criatividade surge a partir de uma atitude que busca superações desafiadoras, a qual foi perceptível também nos documentos e relatos referentes ao desenvolvimento das ações da escola, ao incentivar os alunos a serem protagonistas de sua aprendizagem de forma prazerosa. 


\section{Referências}

ANDRÉ, M. E. D. A. de. O que é um estudo de caso qualitativo em educação. Revista da FAEEBA: Educação e contemporaneidade, Salvador, v. 22. N. 40, jul./dez. 2013. p. 95-103

ESCOLA MUNICIPAL DE TEMPO INTEGRAL DANIEL BATISTA. Projeto Político Pedagógico - PPP. Palmas: Escola Municipal de Tempo Integral Daniel Batista, 2014a.

ESCOLA MUNICIPAL DE TEMPO INTEGRAL DANIEL BATISTA. Projeto: Declamadores de poesias. XIII Concurso: $O$ sítio do pica pau amarelo. Escola Municipal de Tempo Integral Daniel Batista. Palmas, 2014b.

ESCOLA MUNICIPAL DE TEMPO INTEGRAL DANIEL BATISTA. Projeto: Lendo na escola. Escola Municipal de Tempo Integral Daniel Batista. Palmas, 2015.

MORAES, M. C. Ecologia dos saberes: complexidade, transdisciplinaridade e educação: novos fundamentos para iluminar novas práticas educacionais. São Paulo: Antakarana/ WHH - Willis Harman House, 2008.

MORIN, E. Os sete saberes necessários à educação do futuro. Tradução de Catarina Eleonora F. da Silva e Jeanne Sawaya. 2. ed. São Paulo: Cortez; Brasília, DF: UNESCO, 2000.

MORIN, E. Introdução ao pensamento complexo. Lisboa: Instituto Piaget, 3a ed. 2001.

MORIN, E. Desafios da transdisciplinaridade e da complexidade. In: AUDY, J. L. N.; MOROSINI, M. C. (Org.). Inovação e interdisciplinaridade na Universidade. Porto Alegre: EDIPUCRS, 2007. p. 22-28

NASCIMENTO, P. L. Parâmetros para análise-síntese de práticas educativas. In: SUANNO, M. V. R. et al. (Org.) Resiliência, criatividade e inovação: potencialidades transdisciplinares na educação. Goiânia: UEG/Ed. América, 2013. p. 75-99.

NICOLESCU, B. O manifesto da transdisciplinaridade. Tradução: Lucia Pereira de Souza. São Paulo: Triom, 1999. 
PRAUN, A. G.; GONÇALVES, D. K. Educação inclusiva: criatividade e ecoformação no entorno escolar. In: TORRE, S. de L.; ZWIEREWICZ, M. (Coord.) Uma escola para o século XXI: escolas criativas e resiliência na educação. Florianópolis: Insular, 2009. p. $139-150$.

RAJADELL, N. A importância das estratégias didáticas em toda ação formativa. In: SUANNO, M. V. R. et al (Org.) Didática e formação de professores: perspectivas e inovações. Goiânia: CEPED Publicações e PUC Goiás, 2012. p. 105-132.

RIBEIRO, O. C. MORAES, M. C. Criatividade em uma perspectiva transdisciplinar: rompendo crenças, mitos e concepções. Brasília: Liber Livro, 2014.

SUANNO, J. H. Adversidade, resiliência e criatividade: uma articulação oportuna? In: SUANNO, M. V. R. et al. (Org.) Resiliência, criatividade e inovação: potencialidades transdisciplinares na educação. Goiânia: UEG/Ed. América, 2013. p. 31-42.

TORRE, S. de 1. Dialogando com a criatividade. Tradutora Cristina Mendes Rodríguez. São Paulo: Madras, 2005.

TORRE, S. de l. Criatividade aplicada: recursos para uma formação criativa. Tradução WIT Languages. São Paulo: Madras, 2008.

TORRE, S. de l.; et al. Decálogo sobre transdisciplinaridade e ecoformação. In: TORRE, S. de la; PUJOL, M. A.; MORAES, M. C. (Org.) Transdisciplinaridade e ecoformação: um novo olhar sobre a educação. Tradução: Suzana Vidigal. São Paulo: Triom, 2008. p. $21-59$.

TORRE, S. de 1. Escolas criativas: escolas que aprendem, criam e inovam. In: TORRE, S. de L.; ZWIEREWICZ, M. (Coord.) Uma escola para o século XXI: escolas criativas e resiliência na educação. Florianópolis: Insular, 2009. p. 55-69.

TORRE, S. de l.; ZWIEREWICZ, M. Projetos criativos ecoformadores. In: TORRE, S. de l.; ZWIEREWICZ, M. (coord.) Uma escola para o século XXI: escolas criativas e resiliência na educação. Florianópolis: Insular, 2009. p. 153-175. 
TORRE, S. de 1.; ZWIEREWICZ, M. Apresentação: relatos para tempos de crise. In: TORRE, S. de 1.; ZWIEREWICZ, M. (Coord.). Criatividade na adversidade: personagens que transformaram situações adversas em oportunidades. Blumenau: Nova Letra, 2012. p. 9-16.

TORRE, S. de l. Criadores na Adversidade e na Crise: Qual é o Segredo? In: TORRE, S. de L.; ZWIEREWICZ, M. (Coord.). Criatividade na adversidade: personagens que transformaram situações adversas em oportunidades. Blumenau: Nova Letra, 2012. p. $19-48$.

ZWIEREWICZ, M. Projetos Criativos Ecoformadores - PCE: uma via metodológica desde e para o paradigma da complexidade. In: TORRE, S. de; et al. (Coord.) Inovando na sala de aula: instituições transformadoras. Blumenau: Nova Letra, 2013. p. 151-175.

Recebido em: 12 abril 2016.

Aceito em: 29 abril 2016. 